\title{
Effects of home on the mental health of British forces serving in Iraq and Afghanistan
}

Kathleen Mulligan, ${ }^{*}$ Norman Jones, ${ }^{*}$ Mark Davies, Peter McAllister, Nicola T. Fear, Simon Wessely and Neil Greenberg

\section{Background}

Most studies of the mental health of UK armed forces focus on retrospective accounts of deployment and few sample personnel while they are deployed.

\begin{abstract}
Aims
This study reports the results of a survey of deployed personnel, examining the perceived impact of events at home and military support for the family on current mental health during the deployment.
\end{abstract}

\section{Method}

Surveys were conducted with 2042 British forces personnel serving in Iraq and Afghanistan. Prevalence of common mental disorders was assessed with the 12-item General Health Questionnaire (GHQ-12) and post-traumatic stress disorder (PTSD) was assessed with the PTSD Checklist Civilian version (PCL-C).

\section{Results}

The prevalence of common mental disorders was $17.8 \%$ and of probable PTSD was $2.8 \%$. Perceived home difficulties significantly influenced the mental health of deployed personnel; the greater the perception of negative events in the home environment, the greater the reporting of adverse mental health effects. This finding was independent of combat exposure and was only partially mitigated by being well led and reporting subjectively good unit cohesion; however, the effect of the totality of home-front events was not improved by the latter. Poor perceived military support for the family had a detrimental impact on deployment mental health.

\section{Conclusions}

The armed forces offer many support services to the partners and families of deployed personnel and ensuring that the efforts being made on their behalf are well communicated might improve the mental health of deployed personnel.

\section{Declaration of interest}

N.G., M.D. and P.M. are full-time members of the UK armed forces. N.J. is a full-time reservist. Both N.G. and N.J. are currently seconded to King's College London. N.F., S.W. and K.M. are employed by King's College London which receives funding from the UK Ministry of Defence. S.W. is also honorary civilian consultant advisor in psychiatry to the British Army and is a trustee of Combat Stress, a UK charity that provides service and support for veterans with mental health problems.
Although there is great interest in understanding factors that contribute to the mental health of UK armed forces personnel, most studies focus on retrospective accounts of deployment and few studies sample personnel while they are deployed. To date most studies that have examined the mental health of military personnel in war zones have concentrated on aspects of the combat environment. However, studies of post-traumatic stress disorder (PTSD) suggest that it is not only traumatic exposure itself that is a risk factor for developing PTSD; other factors, including the experience of other stressful life events and lack of social support, are also important. ${ }^{1}$ A small number of studies have reported the importance of non-combat factors for deployed military personnel. For example, negative aspects of deployment reported by US troops deployed to Bosnia included being away from family, missing important family events and the deterioration of marital relationships. ${ }^{2}$ Although Newby et al did not determine whether these events had an adverse impact on mental health, a retrospective study of Israeli soldiers who had fought in the Yom Kippur War and had 'battle shock' found that many had experienced family stresses before or during the war, suggesting an interactive effect between war trauma and psychosocial stressors. ${ }^{3}$ Data collected retrospectively from US 1991 Gulf War veterans found that concerns about the effect of deployment on family, and other relationships, were associated with anxiety and symptoms of post-traumatic stress. ${ }^{4}$ Browne et al

*These authors contributed equally to the work. reported that the greater prevalence of probable PTSD among reserves compared with regular British troops deployed to Iraq was partly explained by reserves reporting more major problems at home during deployment. ${ }^{5}$ Home-front concerns experienced during deployment in Iraq by regular US soldiers were also found to be significantly associated with an increase in PTSD from pre- to post-deployment. ${ }^{6}$ In addition to these aspects of the non-operational setting, operational factors such as having a combat role, being deployed in a forward area and the perceived threat of death or serious injury are known to adversely influence mental health, whereas protective factors include good leadership, unit cohesion and morale..$^{7-11}$

These studies collected data about deployment experiences retrospectively, but there has been a recent US study during deployment to examine combat and non-combat stressors (among other factors) and their relation to mental health. ${ }^{12}$ The UK has now followed suit with the first Operational Mental Health Needs Evaluation (OMHNE) surveys of personnel serving in Iraq and Afghanistan. ${ }^{10}$ The current paper analyses data collected in the OMHNE surveys to examine the influence of factors relating to home and family life on the psychological well-being of UK armed forces personnel while on deployment.

\section{Method}

Data were collected in two operational theatres - in Iraq between January and February 2009 during Operation (Op) TELIC 13 and 
in Afghanistan between January and February 2010 during Op HERRICK 11. Ops TELIC and HERRICK are the respective codenames for UK military operations in Iraq since 2003 and Afghanistan since 2002. Eligible participants were members of the UK armed forces who were deployed on Op TELIC 13 or Op HERRICK 11 during the study data collection periods. The target sample size was $15 \%$ of deployed personnel, a total of 600 from Op TELIC 13 and 1425 from Op HERRICK 11. Tactical and logistical barriers prevented the use of a wholly randomised sampling process; however, the study team ensured that at least half of those surveyed were either stationed outside of the main base areas, including patrol bases and forward operating bases, or were in units that regularly deployed out of the main bases to more hazardous areas (for example the quick reaction force). When the survey teams arrived at a particular location, all the available personnel at that location were surveyed unless they were on duty (for example manning the checkpoints/guard towers) or were asleep off duty.

Data were collected using self-reported questionnaires. The survey team travelled to the locations where potential participants were based to advise personnel about the study and conduct recruitment. Personnel were advised that participation was voluntary and that all information was confidential. Questionnaire completion took approximately $25 \mathrm{~min}$.

The study questionnaire included questions on sociodemographic and military characteristics, deployment experiences and concerns, and non-combat-related experiences. The primary mental health outcomes were common mental disorders and symptoms of PTSD. The 12-item General Health Questionnaire $(\text { GHQ-12) })^{13}$ is widely used as a measure of 'common mental disorders'; it assesses aspects of anxiety and depression, social dysfunction and loss of confidence. Responses are scored 0 or 1 , giving a possible total score ranging from 0 to 12 . Respondents were classified as possible clinical 'cases' on this measure if they scored four or more. The 17-item Post Traumatic Stress Disorder Checklist - Civilian version (PCL-C) ${ }^{14}$ was used to assess symptoms of PTSD. The PCL-C has a possible range of 17-85 and 'caseness' was defined as a score of 50 or more.

Combat exposure was assessed with a 17 -item measure ${ }^{15}$ that asked respondents about their exposure to a number of potentially traumatic combat events, for example, coming under fire, having an improvised explosive device explode near them or handling human remains. The scale was scored by calculating the sum of the number of events experienced, giving a possible score of 0-17. Experience of non-combat events was assessed with a measure adapted from US surveys of military health. ${ }^{12}$ Questions asked if respondents had experienced: (a) the birth of a child, (b) the death or serious illness of a relative, loved one or child, (c) a spouse or partner leaving, (d) serious financial problems, (e) problems with their children, or (f) other major problems at home while deployed. In the analysis, we combined item (c) with two other questions asking whether the respondent or their partner was planning divorce or separation, to create a new binary variable, 'relationship breakdown'. The items were summed to give a non-combat event scale with a possible score of 0-6. Participants were asked about deployment concerns, including whether they were troubled by being separated from their family or by difficulties communicating with home (response options: no, a little, a lot). A question about the provision and adequacy of military support for the family while they were away on deployment was also included.

Approval for the study was granted by the Ministry of Defence Research Ethics Committee (MODREC). All participants gave written informed consent.

\section{Analysis}

Analyses were conducted in STATA 10.1 for Windows. Statistical significance was defined as $P<0.05$. We compared the two deployment samples and, as previous research has reported greater home-front problems and mental health problems among reserves, we also compared regulars and reserves. The comparisons were made using $\chi^{2}$ or Fisher's exact tests for categorical variables and $t$-tests or Mann-Whitney $U$-tests for continuous variables.

Associations between risk factors and mental health outcomes were examined with multivariable regression analyses. These analyses combined the data from the two operational theatres into a single sample. Risk factors for scoring above the cut-off for classification as a probable clinical 'case' on the GHQ-12 were examined using binary logistic regression analysis. As only a small number scored as PTSD 'cases', the PCL-C was analysed as a continuous measure of PTSD symptoms. Data were highly positively skewed and could not be transformed to a normal distribution, therefore negative binomial regression was conducted. The PCL-C total score was recoded from 17-85 to 0-68 for this analysis, giving the models a better fit. The multivariable analyses controlled for demographic variables and, to control for differences in the operational environments, analyses were adjusted for the operational theatre in which data were collected and for self-reported combat exposure. As leadership and unit cohesion have been found to protect against mental health problems, we also adjusted for these variables.

The relationship between the number of non-combat events experienced $(0,1,2+)$ and concern relating to separation from home and communicating with home was examined with Spearman correlation analysis.

\section{Results}

In total 2042 participants were recruited, 611 from Op TELIC and 1431 from Op HERRICK, representing approximately 15\% and $16 \%$ of those deployed to the respective operational theatres. Few personnel refused participation; response rates were $99.8 \%$ in Op TELIC and $99.6 \%$ in Op HERRICK. Data available to us on the service and rank of the total population deployed on Op TELIC 13 showed that the OMHNE TELIC sample was broadly similar to the total deployed population on these variables. ${ }^{10,11}$

Overall, the prevalence of common mental disorders was $17.8 \%$ and of probable PTSD was $2.8 \%$. The Op HERRICK sample had a greater proportion of army personnel, and a smaller proportion of female participants than Op TELIC (online Table DS1), however gender was no longer significantly different between the two samples after adjusting for service (adjusted odds ratio $(\mathrm{OR})=0.81,95 \%$ CI $0.58-1.12$ ). Participants in the Op HERRICK population reported greater exposure to potentially traumatic combat events but exposure to non-combat events did not differ.

There were no statistically significant differences between regular and reserve personnel in the number of non-combat events experienced or in mental health outcomes on either the GHQ-12 or PCL-C (data available from authors on request).

Spearman correlation analyses showed highly significant relationships between experiencing more non-combat (home front) events and both greater concerns about being separated from one's family during deployment $\left(r_{\mathrm{s}}=0.22, P<0.0001\right)$ and about difficulties communicating with home $\left(r_{\mathrm{s}}=0.17\right.$, $P<0.0001)$. Difficulties communicating with home and concerns about being separated from one's family were both associated with greater severity of PTSD symptoms and also scoring above the cut-off on the GHQ-12. These findings remained after adjusting 
for demographic and operational variables, unit cohesion and leadership (Tables 1 and 2).

All of the non-combat experiences, with the exception of birth of a child, were associated with scoring above the cut-off on the GHQ-12 and/or reporting greater severity of PTSD symptoms (Tables 1 and 2). Experiencing more than one of these events significantly increased the risk of poorer mental health on GHQ-12 (online Table DS2) and PCL-C (online Table DS3). These findings remained after adjusting for demographic and operational variables, unit cohesion and leadership.

Mental health was not related to whether or not personnel were in a long-term relationship. However, relationship breakdown (defined as having a spouse/partner who had left during the deployment, currently planning to separate or being aware that their partner was intending to separate) was reported by $162(7.9 \%)$ participants and the risk of this occurring increased as the tour progressed ( $0-4$ weeks $3.9 \%, 5-8$ weeks $6.5 \%, 9-16$ weeks $7.8 \%, 17-26$ weeks $8.8 \%, 27$ or more weeks $12.3 \%$; the $\chi^{2}$ for trend of odds was 8.0, $P<0.005)$. Those who reported relationship breakdown were more likely to score above the cutoff on the GHQ-12, which remained significant after adjusting for demographic and operational variables but was no longer significant when leadership and unit cohesion were added to the model (Table 1). Those who reported relationship breakdown also reported greater severity of PTSD symptoms, an effect that remained after adjusting for demographic variables, but was no longer significant after further adjusting for operational variables (Table 2).
Having serious financial problems, problems with children and being faced with major home-front problems were all significantly associated with GHQ caseness (Table 1) and severity of PTSD symptoms (Table 2) after adjusting for demographic and operational variables. Experiencing the death or serious illness of a loved one was also associated with PTSD symptom severity (Table 2).

Many single respondents and those without children did not answer the question concerning military support for spouse/ partner/family, therefore analysis of this question is restricted to participants who reported being in a long-term relationship and/or having children $(n=1415)$. Compared with personnel who felt that the military had provided sufficient help to their families while deployed, the chance of poor mental health on the GHQ-12 (online Table DS2) and PCL-C (online Table DS3) was greater in those who perceived that their family had been provided with insufficient support or no support. These findings remained after adjusting for demographic and operational variables, and in the case of PTSD symptom severity, also remained after further adjusting for cohesion and leadership.

\section{Discussion}

Whereas most military studies of the mental health effects of deployment focus on operational stressors, and combat exposure in particular, this is the first UK study to examine the impact of family events occurring at home on the mental health of personnel

Table 1 Association of non-combat events with scoring above the cut-off on the General Health Questionnaire

\begin{tabular}{|c|c|c|c|c|c|c|}
\hline & \multirow[b]{2}{*}{$n^{\mathrm{a}}$} & \multicolumn{5}{|c|}{ General Health Questionnaire (GHQ-12) } \\
\hline & & $\begin{array}{l}\text { GHQ 'cases' } \\
\quad n(\%)\end{array}$ & $\begin{array}{l}\text { Unadjusted OR } \\
\qquad(95 \% \mathrm{Cl})\end{array}$ & $\begin{array}{l}\text { Adjusted } \mathrm{OR}^{\mathrm{b}} \\
\quad(95 \% \mathrm{Cl})\end{array}$ & $\begin{array}{l}\text { Adjusted } \mathrm{OR}^{\mathrm{C}} \\
\quad(95 \% \mathrm{Cl})\end{array}$ & $\begin{array}{l}\text { Adjusted } \mathrm{OR}^{\mathrm{d}} \\
\qquad(95 \% \mathrm{Cl})\end{array}$ \\
\hline \multicolumn{7}{|c|}{$\begin{array}{l}\text { Non-combat events } \\
\text { Birth of a child }(n=2009)\end{array}$} \\
\hline Yes & 55 & $11(20.0)$ & $1.20(0.61-2.36)$ & $1.24(0.63-2.43)$ & $1.29(0.65-2.57)$ & $1.26(0.59-2.69)$ \\
\hline No & 1954 & $344(17.6)$ & 1.00 & 1.00 & 1.00 & 1.00 \\
\hline \multicolumn{7}{|c|}{ Death or serious illness of a loved one $(n=2014)$} \\
\hline Yes & 245 & $50(20.4)$ & $1.24(0.89-1.73)$ & $1.26(0.90-1.77)$ & $1.20(0.84-1.72)$ & $1.15(0.79-1.67)$ \\
\hline No & 1769 & $308(17.4)$ & 1.00 & 1.00 & 1.00 & 1.00 \\
\hline \multicolumn{7}{|c|}{ Had serious financial problems $(n=2007)$} \\
\hline Yes & 82 & $26(31.7)$ & $2.38(1.47-3.87)$ & $2.28(1.39-3.75)$ & $2.21(1.30-3.77)$ & $2.19(1.26-3.82)$ \\
\hline No & 1925 & $329(17.1)$ & 1.00 & 1.00 & 1.00 & 1.00 \\
\hline \multicolumn{7}{|c|}{ Problems with children $(n=2008)$} \\
\hline Yes & 127 & $35(27.6)$ & $1.87(1.24-2.82)$ & $2.30(1.50-3.53)$ & $2.20(1.41-3.45)$ & 2.00. (1.25-3.20) \\
\hline No/not applicable & 1881 & $321(17.1)$ & 1.00 & 1.00 & 1.00 & 1.00 \\
\hline \multicolumn{7}{|c|}{$\begin{array}{l}\text { Faced other major problems at home } \\
\text { while deployed }(n=2011)\end{array}$} \\
\hline Yes & 221 & $71(32.1)$ & $2.51(1.84-3.42)$ & $2.65(1.93-3.64)$ & $2.41(1.72-3.36)$ & $2.22(1.56-3.16)$ \\
\hline No & 1790 & $284(15.9)$ & 1.00 & 1.00 & 1.00 & 1.00 \\
\hline \multicolumn{7}{|c|}{$\begin{array}{l}\text { Relationship breakdown (self or partner } \\
\text { planning divorce/separation or spouse/partner } \\
\text { left) ( } n=2029)\end{array}$} \\
\hline Yes & 162 & $42(25.9)$ & $1.75(1.20-2.56)$ & $1.76(1.20-2.56)$ & $1.57(1.06-2.33)$ & $1.33(0.88-2.02)$ \\
\hline No & 1867 & $318(17.0)$ & 1.00 & 1.00 & 1.00 & 1.00 \\
\hline \multicolumn{7}{|c|}{ In-theatre family-related events } \\
\hline \multicolumn{7}{|c|}{ Communication difficulties ( $n=1982)$} \\
\hline No or little & 1731 & $270(15.6)$ & 1.00 & 1.00 & 1.00 & 1.00 \\
\hline \multicolumn{7}{|c|}{ Separation from family $(n=1982)$} \\
\hline Yes & 249 & $96(38.6)$ & $1.87(1.62-2.16)$ & $1.95(1.69-2.26)$ & $1.99(1.71-2.32)$ & $1.94(1.66-2.28)$ \\
\hline No or little & 1733 & $264(15.2)$ & 1.00 & 1.00 & 1.00 & 1.00 \\
\hline \multicolumn{7}{|c|}{$\begin{array}{l}\text { OR, odds ratio. } \\
\text { Statistically significant results }(P<0.05) \text { are highlighted in bold. } \\
\text { a. Numbers may not add up to totals due to missing data. } \\
\text { b. Adjusted for age, gender, service and rank. } \\
\text { C. Adjusted for age, gender, service, rank, operation and combat exposure. } \\
\text { d. Adjusted for age, gender, service, rank, operation, combat exposure, unit cohesion and leadership. }\end{array}$} \\
\hline
\end{tabular}




\begin{tabular}{|c|c|c|c|c|c|}
\hline & \multicolumn{5}{|c|}{ PTSD Checklist - Civilian version (PCL-C) } \\
\hline & $n^{\mathrm{a}}$ & $\begin{array}{l}\text { Unadjusted IRR } \\
\quad(95 \% \mathrm{Cl})\end{array}$ & $\begin{array}{l}\text { Adjusted IRR } \\
\quad(95 \% \mathrm{Cl})\end{array}$ & $\begin{array}{l}\text { Adjusted IRR } \\
\quad(95 \% \mathrm{Cl})\end{array}$ & $\begin{array}{l}\text { Adjusted IRR } \\
\quad(95 \% \mathrm{Cl})\end{array}$ \\
\hline \multicolumn{6}{|c|}{$\begin{array}{l}\text { Non-combat events } \\
\text { Birth of a child }(n=1971)\end{array}$} \\
\hline Yes & 53 & $1.20(0.61-2.36)$ & $1.15(0.78-1.68)$ & $1.08(0.73-1.58)$ & $1.10(0.74-1.64)$ \\
\hline No & 1918 & 1.00 & 1.00 & 1.00 & 1.00 \\
\hline \multicolumn{6}{|c|}{ Death or serious illness of a loved one $(n=1976)$} \\
\hline Yes & 240 & $1.45(1.19-1.75)$ & $1.43(1.18-1.73)$ & $1.36(1.12-1.65)$ & $1.30(1.08-1.57)$ \\
\hline No & 1736 & 1.00 & 1.00 & 1.00 & 1.00 \\
\hline \multicolumn{6}{|c|}{ Had serious financial problems $(n=1970)$} \\
\hline Yes & 80 & $2.14(1.56-2.92)$ & $2.01(1.47-2.75)$ & $1.81(1.31-2.52)$ & $1.80(1.31-2.50)$ \\
\hline No & 1890 & 1.00 & 1.00 & 1.00 & 1.00 \\
\hline \multicolumn{6}{|c|}{ Problems with children $(n=1969)$} \\
\hline Yes & 125 & $1.43(1.10-1.84)$ & $1.51(1.17-1.95)$ & $1.51(1.17-1.95)$ & $1.39(1.07-1.79)$ \\
\hline No/not applicable & 1844 & 1.00 & 1.00 & 1.00 & 1.00 \\
\hline \multicolumn{6}{|c|}{$\begin{array}{l}\text { Faced other major problems at home while deployed } \\
(n=1973)\end{array}$} \\
\hline Yes & 219 & $2.05(1.69-2.50)$ & $2.05(1.69-2.49)$ & $1.96(1.61-2.39)$ & $1.87(1.54-2.27)$ \\
\hline No & 1754 & 1.00 & 1.00 & 1.00 & 1.00 \\
\hline \multicolumn{6}{|c|}{$\begin{array}{l}\text { Relationship breakdown (self or partner planning } \\
\text { divorce/separation or spouse/partner left) ( } n=1991)\end{array}$} \\
\hline Yes & 160 & $1.33(1.05-1.67)$ & $1.27(1.01-1.59)$ & $1.20(0.96-1.51)$ & $1.10(0.88-1.38)$ \\
\hline No & 1831 & 1.00 & 1.00 & 1.00 & 1.00 \\
\hline \multirow{2}{*}{\multicolumn{6}{|c|}{$\begin{array}{l}\text { Communicating with home and separation } \\
\text { Difficulties communicating with home }(n=2012)\end{array}$}} \\
\hline & & & & & \\
\hline Yes & 257 & $0.37(0.28-0.46)$ & $1.44(1.32-1.58)$ & $1.37(1.25-1.51)$ & $1.31(1.19-1.44)$ \\
\hline No or little & 1755 & 1.00 & 1.00 & 1.00 & 1.00 \\
\hline \multicolumn{6}{|c|}{ Troubled by separation from family $(n=2012)$} \\
\hline Yes & 250 & $0.42(0.33-0.51)$ & $1.51(1.38-1.65)$ & $1.47(1.34-1.61)$ & $1.43(1.31-1.57)$ \\
\hline No or little & 1762 & 1.00 & 1.00 & 1.00 & 1.00 \\
\hline \multicolumn{6}{|c|}{$\begin{array}{l}\text { IRR, incidence rate ratios. } \\
\text { Statistically significant results }(P<0.05) \text { are highlighted in bold. } \\
\text { a. Numbers may not add up to totals due to missing data. } \\
\text { b. Adjusted for age, gender, service and rank. } \\
\text { c. Adjusted for age, gender, service, rank, operation and comba } \\
\text { d. Adjusted for age, gender, service, rank, operation, combat ex }\end{array}$} \\
\hline
\end{tabular}

while they are deployed. There are a number of important findings. First, more negative perceptions of military support for the family reported by deployed personnel were associated with more negative reports of mental health status. Second, this effect was independent of operational theatre and combat intensity. Third, whereas many studies report on the positive effects of good unit cohesion and leadership in theatre, which have been described as important mitigators of traumatic stress in particular, we found that these two factors were less able to offset the effects of perceived poor military support for the family, especially with regard to symptoms of PTSD.

Research that has examined the relationship between home life and deployment has usually examined the impact of deployment on the family rather than the impact of issues at home on deployed personnel. ${ }^{16-18}$ This study shows that there is a reciprocal relationship of home events on the mental health of deployed personnel themselves. These findings are not unexpected as studies of risk factors for psychological problems include multiple stressors and lack of social support. ${ }^{19,20}$ We found that a number of non-combat events, including death or serious illness of a loved one, serious financial difficulties, unspecified major home-front difficulties and problems with children, added to the totality of deployment stress. Even after adjusting for subjective good leadership and cohesion, which are thought to mitigate deployment stress, symptoms of common mental disorder and PTSD persisted, suggesting that concerns about major issues at home have an independent effect for a substantial minority of personnel. We also found a significant adverse mental health effect for experiencing a relationship breakdown during deployment. This was not surprising as being in a confiding relationship is thought to go someway to offsetting the effects of stress ${ }^{21}$ and relationship breakdown is therefore likely to have an impact on personal resilience. We found that when we adjusted for leadership and cohesion in the model, the effect of relationship breakdown became non-significant for symptoms of common mental disorder suggesting that something can be done by operational commanders to mitigate the adverse mental health effects of relationship breakdown. When we adjusted for operational exposure, the impact of relationship breakdown on PTSD symptom severity was not significant, suggesting that these symptoms may be related to exposure to potentially traumatic events rather than the direct impact of relationship breakdown.

We found that personnel who experienced more home events also reported more concerns about family separation and communicating with home. The latter has been identified as a significant stressor in the research literature; Bell et $a l^{22}$ describe how, during a US deployment in Somalia, difficulties communicating with home predicted the level of spouse stress during the deployment. Separation from one's family is an inevitable part of military service and communication restrictions are also unavoidable in austere locations, particularly during combat operations. Although the existing in-theatre communications with home are numerous (including email and telephones) and the provision of wireless internet services is becoming more available in main base areas, it may be that other forms of communication with home might be considered by deployed personnel, such as 
hand-written letters and audio recordings, and that the systems currently available should be made more widely available in forward areas. It is also worth considering that access to immediate communication with home may have a downside where it offers a practical and immediate way of intervening in homeland problems and a method of directly responding to emotional disclosure that might otherwise be resolved by the passage of time. ${ }^{23}$ It might also be possible (during pre-deployment preparation and training) for personnel to be taught specific strategies for dealing with various communication mediums. For instance, a measured letter or email might be a more useful ploy than using valuable satellite telephone time attempting to resolve difficult homeland issues.

The UK armed forces formally provide a range of welfare support for the families of both deployed and non-deployed personnel, including assistance with housing, child care, financial hardship and, in some cases, basic supportive counselling. This study found an association between dissatisfaction with the perceived provision of family support and poorer mental health. If deployed personnel could be confident that adequate homeland support was in place, it is possible that concerns about separation and perceived problems on the home front could be reduced and the impact on mental health lessened. This highlights the importance of ensuring that a high-quality 'rear-party' (unit personnel charged with maintaining the home base) is in place and that their efforts are communicated forward to the operational theatre. Although we did not examine the differential effects of home-front stress on individual augmentees (personnel who deploy with a unit other than their usual pre-deployment unit) this is likely to be quite challenging for this group as a substantial 'rear party' and the associated home-front support may not be in place.

Data were collected in two different operational environments. Op TELIC data were collected as operations in Iraq were coming to an end and operational intensity was low. This contrasted with the much higher operational tempo in Afghanistan. The finding that the impact of home life on mental health is independent of such differences in the operational environment is important as it suggests that our results may be generalisable to operations with varying levels of combat intensity and that universal homeland stressor mitigation strategies may be required irrespective of operational tempo. However, care should be taken when extrapolating to peacekeeping of humanitarian operations where the stresses of deployment could be quite different.

\section{Limitations}

Deriving data from non-random samples increases the possibility of selection bias; however, the survey team made considerable efforts to minimise such bias by sampling personnel from several locations and varying types of operational unit in both operational theatres. Also, we report associations rather than cause in this paper and it may be that those with poorer mental health may perceive greater problems at home while deployed. Whatever the causal direction, it is still important that family support mechanisms are in place and known to be so by deployed personnel. Finally, it is important to emphasise that our data reports perceptions, and that the perceptions of poor support may not match reality. Notwithstanding that, the fact that perceptions alone influenced mental health emphasises the importance of ensuring not only that families are supported, but that they are perceived to be supported.

\section{Implications}

This study demonstrates a substantial link between home concerns and mental health in the operational theatre and it may be beneficial for operational commanders to ensure that deployed personnel feel confident that the military is able to provide meaningful support for their family and loved ones at home. Efforts such as increasing the provision of support to families/ loved ones and ensuring that deployed personnel are made aware of the support being provided may help. We suggest that the role of personnel who maintain the integrity of the home base, known as the 'rear party' in the UK, and also military support and welfare services, may act as important contributors to the mental health of the deployed force.

Improving the visibility of home-front support activities may have a positive impact on the mental health of those deployed. In addition, routine pre-deployment preparatory and psychoeducational briefs might benefit from imparting information about various communication strategies to use while deployed and information about the various support services available, to combat negative perceptions of family support. However, providing support may prove to be challenging when families do not live near the home base or in a garrison town. This is especially relevant for reservists ${ }^{24}$ and for those deployed as individual augmentees (details available from the authors on request).

Kathleen Mulligan, PhD, Norman Jones, MSc, Academic Centre for Defence Mental Health, King's College London, UK; Mark Davies, MSc, British Army, TRiM Training Team, Camberley; Peter McAllister, MSC, MRCPsych, Department of Community Mental Health, Queen Elizabeth Memorial Health Centre, Tidworth Nicola T. Fear, DPhil (Oxon), Simon Wessely, MD, FRCPsych, Neil Greenberg, MD, MRCPsych, Academic Centre for Defence Mental Health, King's College London, UK

Correspondence: Norman Jones, Academic Centre for Defence Mental Health King's College London, Weston Education Centre, 10 Cutcombe Road, London SE5 9RJ, UK. Email: norman.jones@kcl.ac.uk

First received 3 Jun 2011, final revision 18 Sep 2011, accepted 26 Oct 2011

\section{Funding}

S.W. is partially funded by the South London and Maudsley NHS Foundation Trust/Institute of Psychiatry National Institute of Health Research (NIHR) Biomedical Research Centre.

\section{References}

1 Brewin CR, Andrews B, Valentine JD. Meta-analysis of risk factors for posttraumatic stress disorder in trauma-exposed adults. J Consult Clin Psychol 2000; 68: 748-66.

2 Newby JH, McCarroll JE, Ursano RJ, Fan Z, Shigemura J, Tucker-Harris Y. Positive and negative consequences of a military deployment. Mil Med 2005; 170: 815-9.

3 Noy S. Stress and personality as factors in the causality and prognosis of combat reaction. In Contemporary Studies in Combat Psychiatry (ed. G Belanky): 21-9. Westport Greenwood Press, 1987.

4 Vogt DS, Pless AP, King LA, King DW. Deployment stressors, gender, and mental health outcomes among Gulf War I veterans. J Trauma Stress 2005; 18: $272-84$.

5 Browne T, Hull L, Horn O, Jones M, Murphy D, Fear NT, et al. Explanations for the increase in mental health problems in UK reserve forces who have served in Iraq. Br J Psychiatry 2007; 190: 484-9.

6 Vasterling JJ, Proctor SP, Friedman MJ, Hoge CW, Heeren T, King LA, et al. PTSD symptom increases in Iraq-deployed soldiers: comparison with nondeployed soldiers and associations with baseline symptoms, deployment experiences, and postdeployment stress. J Trauma Stress 2010; 23: 41-51.

7 Iversen AC, Fear NT, Ehlers A, Hacker Hughes J, Hull L, Earnshaw M, et al. Risk factors for post-traumatic stress disorder among UK Armed Forces personnel. Psychol Med 2008; 38: 511-22.

8 Castro C. Impact of combat on the mental health and well-being of soldiers and marines. Smith Coll Stud Soc Work 2009; 79: 247-62.

9 Fear NT, Jones M, Murphy D, Murhpy D, Hull L, Iversen AC, et al. The consequences of deployment to Iraq and Afghanistan on the mental health of the UK armed forces: a cohort study. Lancet 2010; 375: 1783-97. 
10 Mulligan K, Jones N, Woodhead C, Davis M, Wessely S, Greenberg N. Menta health of UK military personnel while on deployment in Iraq. Br J Psychiatry 2010; 197: 405-10.

11 Jones $\mathrm{N}$, Seddon R, Fear NT, McAllister $\mathrm{P}$, Wessely S, Greenberg N. Leadership, cohesion, morale and the mental health of UK Armed Forces in Afghanistan. Psychiatr Interpers Biol Process 2012; 75: March.

12 Office of the Surgeon Multi-National Force-Iraq and Office of the Command Surgeon Mental Health Advisory Team (MHAT) V. Operation Iraqi Freedom 06-08: Iraq. Operation Enduring Freedom 8: Afghanistan. Office of the Surgeon Multi-National Force-Iraq and Office of the Command Surgeon, 2008

13 Goldberg D, Williams P. A User's Guide to the General Health Questionnaire. nferNelson, 1988.

14 Weathers FW, Litz, BT, Huska JA, Keane TM. PTSD Checklist - Civilian Version. Boston National Center for PTSD, Behavioral Science Division, 1994.

15 Hoge CW, Castro CA, Messer SC, McGurk D, Cotting DI, Koffman RL. Combat duty in Iraq and Afghanistan, mental health problems, and barriers to care. N Engl J Med 2004; 351: 13-22.

16 Dandeker C, French C, Birtles C, Wessley S. Deployment experiences of British Army wives before, during and after deployment: satisfaction with military life and use of support networks. In Human Dimensions in Military Operations - Military Leaders' Strategies for Addressing Stress and Psychological Support. Meeting Proceedings RTO-MP-HFM-134 Paper 38: 38-1-38-20. RTO, 2006 (http://www.dtic.mil/cgi-bin/ GetTRDoc? Location=U2\&doc=GetTRDoc.pdf\&AD=ADA472730).
17 Eaton KM, Hoge CW, Messer SC, Whitt AA, Cabrera OA, McGurk D, et al. Prevalence of mental health problems, treatment need, and barriers to care among primary care-seeking spouses of military service members involved in Iraq and Afghanistan deployments. Mil Med 2008; 173: 1051-6.

18 McFarlane AC. Military deployment: the impact on children and family adjustment and the need for care. Curr Opin Psychiatry 2009; 22: 369-73.

19 Batterham PJ, Christensen H, Mackinnon AJ. Modifiable risk factors predicting major depressive disorder at four year follow-up: a decision tree approach. BMC Psychiatry 2009; 9: 75.

20 Moak ZB, Agrawal A. The association between perceived interpersonal social support and physical and mental health: results from the National Epidemiological Survey on Alcohol and Related Conditions. J Public Health (Oxf) 2010; 32: 191-201.

21 Cohen S, Wills TA. Stress, social support, and the buffering hypothesis. Psychol Bull 1985; 98: 310-57.

22 Bell D, Schumm W, Knott B, Ender MG. The Desert Fax: a research note on calling home from Somalia. Armed Forces Soc 1999; 25: 509-21.

23 Greene T, Buckman J, Dandeker, C, Greenberg N. How communication with families can both help and hinder service members' mental health and occupational effectiveness on deployment. Mil Med 2010; 175: 750-8.

24 Dandeker C, Eversden-French C, Greenberg N, Hatch S, Riley P, van Staden L, et al. Laying down their rifles: the changing influences on the retention of volunteer British Army reservists returning from Iraq, 2003-2006. Armed Forces Soc 2010; 36: 264-89.

\title{
Woyzeck (1837) by Georg Buchner, 1813-37
}

\author{
lain McClure
}

Woyzeck inspired many of the key innovators in Western theatre, since its 1913 Munich premiere, including Brecht and Beckett. Although short in length, it is endlessly innovative and exciting, on many levels. The simple plot includes a theme of medical negligence. A doctor, deluded by his social status, enrolls our humble protagonist into a study of the physiological and psychiatric effects of an exclusive diet of peas. The doctor's disinterest in his subject's well-being is dramatic and tragic. Woyzeck becomes psychotic and murders Marie, his beloved. The play's contagious power lives in its interweaving of scabrous satire and precocious compassion. 